\title{
Heterologous Expression of Genes Mediating Enhanced Fungal Resistance in Transgenic Wheat
}

\author{
Klaus H. Oldach, Dirk Becker, and Horst Lörz \\ Institute for Applied Molecular Plant Biology, AMPII, University of Hamburg, Ohnhorststr. 18, 22609 \\ Hamburg, Germany \\ Submitted 28 November 2000; Accepted 26 February 2001.
}

\begin{abstract}
Three cDNAs encoding the antifungal protein Ag-AFP from the fungus Aspergillus giganteus, a barley class II chitinase and a barley type I RIP, all regulated by the constitutive Ubiquitin1 promoter from maize, were expressed in transgenic wheat. In 17 wheat lines, stable integration and inheritance of one of the three transgenes has been demonstrated over four generations. The formation of powdery mildew (Erysiphe graminis f. sp. tritici) or leaf rust (Puccinia recondita f. sp. tritici) colonies was significantly reduced on leaves from afp or chitinase II- but not from rip I-expressing wheat lines compared with nontransgenic controls. The increased resistance of afp and chitinase II lines was dependent on the dose of fungal spores used for inoculation. Heterologous expression of the fungal afp gene and the barley chitinase II gene in wheat demonstrated that colony formation and, thereby, spreading of two important biotrophic fungal diseases is inhibited approximately 40 to $50 \%$ at an inoculum density of 80 to 100 spores per $\mathrm{cm}^{2}$.
\end{abstract}

High yields of elite wheat cultivars are often reduced severely by epidemically spreading diseases. Among wheat pathogens, fungi represent the largest group. Actual control of fungal diseases is based mainly on various husbandry techniques such as crop rotation, the use of agrochemicals, and breeding for resistant cultivars. Nevertheless, fungi regularly cause yield losses of approximately $20 \%$ in wheat (Oerke et al. 1994; Wiese 1991). An additional method to achieve yield security might be created by the genetic engineering of cereals.

Candidate genes for the transformation of wheat for enhanced fungal resistance include those that encode components of the natural defense response of plants. Ribosomeinactivating proteins (RIPs) specifically cleave a highly conserved adenine residue from the large rRNA of the large ribosomal subunit, which results in the inhibition of translation elongation (Hartley et al. 1996). The cytosolic type I RIP from barley endosperm does neither inactivate plant ribosomes in vitro (Leah et al. 1991; Taylor et al. 1994) nor if expressed in planta (transgenic tobacco), but it does inhibit fungal growth (Jach et al. 1995; Logemann et al. 1992). A further barley seed protein, the secreted chitinase II, belongs to "pathogenesis-

Corresponding author: H. Lörz;

E-mail: loerzamp@botanik.uni-hamburg.de related" proteins and possesses well-known antifungal activity by hydrolyzing fungal cell wall constituents (Kitajima and Sato 1999; Stintzi et al. 1993).

The synthesis of antimicrobial proteins is not restricted to plant species but seems to be ubiquitous in nature (Hancock and Lehrer 1998). The mould Aspergillus giganteus secretes the antifungal protein $A g$-AFP (Wnendt et al. 1994), which displays inhibitory effects on the growth of phytopathogenic fungi. Presumably, toxicity comes from an interaction of positively charged sites of the small protein with negatively charged phospholipids of susceptible fungal membranes (Lacadena et al. 1995).

The fast and effective activation of defense mechanisms is crucial to prevent an infection and seems to be the main difference between resistant and susceptible plants (Yang et al. 1997). The constitutively expressed afp, chitinase II, or rip I in transgenic wheat plants represent potential defense mechanisms, which are active even before an infection takes place.

In this paper, we report the stable transformation of bread wheat by the transfer of cDNAs encoding three differently acting antifungal proteins. In addition, comparisons of the transgenic lines, with respect to their resistance against two economically important biotrophic fungal pathogens Erysiphe graminis f. sp. tritici (powdery mildew of wheat) and Puccinia recondita f. sp. tritici (leaf rust of wheat), are presented.

\section{RESULTS}

Genetic transformation of wheat.

The commercial bread wheat cultivars Florida and Combi (Triticum aestivum L.) served as donor plants for immature embryos, which were used as target tissue for biolistic transformation experiments. In each experiment, one of the plant expression vectors pubi2afp, pubi.chi, or pubi2rip was cobombarded with p35SAcS containing the bar gene as selection marker (Fig. 1), mediating tolerance to the herbicide Basta. After selection and subsequent genomic Southern blot analysis, 24 regenerants that showed a complete integration of the bar gene (not shown) were identified, indicated by the 0.56-kb Bam HI fragment (Fig. 1). The transformation frequency ranged from 0.3 to $2.6 \%$ in single bombardments with a mean of approximately $0.9 \%$ for plants containing an active bar gene.

In 17 independent $\mathrm{T}_{0}$ plants, the cotransformed pubi2afp, pubi.chi, or pubi2rip construct was detected by genomic 
Southern blot analysis, as shown for five plants containing the barley rip I gene (Fig. 2).

The use of uncut, EcoRI- and HindIII-EcoRI-digested genomic DNA from each $\mathrm{T}_{0}$ plant proves that signals after hybridization with the labeled Ubiquitin 1 promoter probe originate from integrated transgene copies; wheat lines possess different integration patterns (genetic independence of transgenic lines); and the whole expression cassette containing promoter, cDNA, and terminator is integrated in the genome. The afp gene was integrated in four lines, the chitinase II gene in eight, and the rip I gene in five lines (Table 1). The estimated number of integrated transgene copies varied from one to eight in these lines.

\section{Transgenic progenies.}

Progenies of $\mathrm{T}_{0}$ plants were sprayed with Basta, and surviving plants were analyzed by genomic Southern blots to verify the cosegregation of afp, chitinase II, or rip I with the bar selection marker. In all 17 lines, a cosegregation of the active bar gene with afp, chitinase II, or rip I in transgenic progenies was demonstrated. Wheat line $6 / 1$, for example, possesses four copies of the pubi.chi construct and shows a consistent pattern of hybridization signals in $T_{1}$ and $T_{2}$ progeny plants, indicating a single integration locus (Fig. 3).

\section{Expression of afp, chitinase II, and rip I.}

Expression of afp, chitinase II, and rip I in transgenic wheat lines was verified by Northern blot analysis of plants in the $T_{0}$,

pubi2afp (4.7 kb)

\begin{tabular}{|c|c|c|}
\hline Ubi1 pro. & intron \\
\hline & Psti \\
\hline
\end{tabular}

pubi.chi $(5.5 \mathrm{~kb})$

$-$\begin{tabular}{|l|l|}
\hline Ubi1 pro. & intron \\
\hline
\end{tabular}

pubi2rip $(5.6 \mathrm{~kb})$

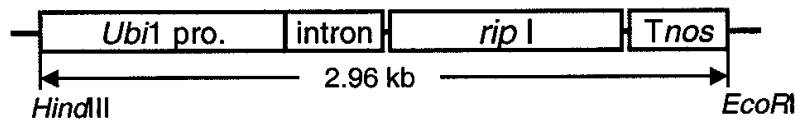

p35SAcS $(4.0 \mathrm{~kb})$

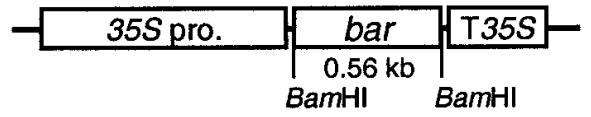

Fig. 1. Constructs used for wheat transformation. Plasmids containing the afp, chitinase II, or rip I gene were cobombarded with plasmid p35SAcS containing the bar selection marker gene. Ubiquitin 1 promoter from maize (Ubi1 pro.) and Tnos terminator sequence from the nopaline synthase gene from Agrobacterium tumefaciens were used in expression vectors pubi2afp, pubi.chi, and pubi2rip. Expression of the bar gene in vector p35SAcS is regulated by the $35 S$ promoter ( $35 S$ pro.) and $35 \mathrm{~S}$ terminator (T35S) from Cauliflower mosaic virus. Restriction sites relevant to the presented Southern blot analysis and the sizes of the Ubil promoter, rip I expression cassette (HindIII-EcoRI fragment containing promoter, cDNA, and terminator), and bar gene (BamHI fragment) are indicated.
$\mathrm{T}_{1}$, and $\mathrm{T}_{2}$ generations as well as selected lines in the $\mathrm{T}_{3}$ generation. Whole cDNAs of afp, chitinase II, and rip I were used as radioactively labeled probes for hybridization of extracted total RNA of transgenic plants (Fig. 4).

In all but one of the 17 lines. a specific expression of the corresponding transgene could be detected in the $\mathrm{T}_{0}$ generation. Ten out of the 12 lines analyzed by Northern blots over the following two generations showed stable expression (Table 2).

The constitutive and stress-inducible activity of the Ubiquitin 1 promoter (Christensen et al. 1992) used in all three antifungal constructs (Fig. 1) was estimated in leaves from transgenic wheat plants expressing afp. The quantification of the afp transcript revealed a more than tenfold increase when total RNA was isolated from rust spore-inoculated plants, in comparison to unstressed plants (Fig. 5), and still more than twice as much transcript as revealed after wounding by cutting the leaves into segments.

\section{Inoculation with mildew and leaf rust.}

Plants of $T_{2}$ progenies were chosen for detached leaf infection assays with spores of E. graminis f. sp. tritici (powdery mildew of wheat) and $P$. recondita $\mathrm{f}$. sp. tritici (leaf rust of wheat). The number of developing fungal colonies on leaf segments from different afp-, chitinase II-, and rip Iexpressing lines from plants expressing only the bar selection marker gene and nontransgenic wild-type controls was compared. A significantly reduced number of mildew colonies was observed in afp- and chitinase II-expressing plants in com-

Table 1. Transgenic $\mathrm{T}_{0}$ wheat plants

\begin{tabular}{lc}
\hline $\begin{array}{l}\mathbf{T}_{\mathbf{0}} \text { plants } \\
\text { with active } \text { bar } \text { gene }\end{array}$ & $\begin{array}{c}\mathbf{T}_{\mathbf{0}} \text { plants } \\
\text { with cotransformed antifungal gene }\end{array}$ \\
\hline 8 & 4 afp \\
8 & 8 chitinase II \\
8 & 5 rip I \\
$\sum 24$ & 17 \\
\hline
\end{tabular}

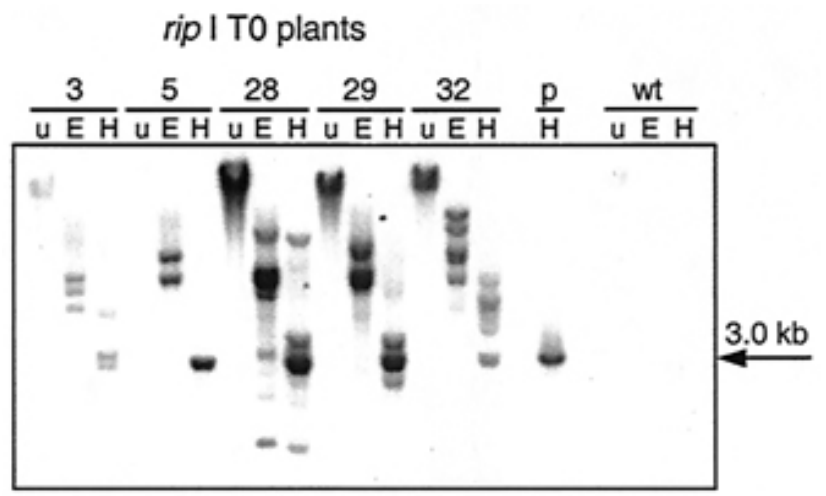

Fig. 2. Southern blot analysis of five rip $\mathrm{I}_{0}$ plants. Genomic DNA isolated from five selected regenerants (3-32) and a wild-type control (wt) was hybridized to a radioactively labeled Ubiquitin 1 promoter PstI fragment from plasmid pubi2afp. Individual plants are characterized in three adjacent lanes: u (uncut DNA); E (restriction with EcoRI), cutting once in the transferred plasmid; $\mathrm{H}$ (double restriction by HindIIIEcoRI), releasing the expected 3.0-kb fragment containing promoter; cDNA; and terminator, as indicated by HindIII-EcoRI restriction of plasmid pubi2rip (lane p). 
parison to the wild-type and rip I-expressing plants. The reduction ranged from 32 to $42 \%$ in afp line $33 / 8$ and chitinase II lines $6 / 1,6 / 8$, and $9 / 9$ at an inoculum density of approximately 100 mildew spores per $\mathrm{cm}^{2}$ (Fig. 6A). Additionally, colony size was bigger on the controls, resulting in stronger sporulation than the colonies on leaves of afp and chitinase II plants.

We obtained similar results when detached leaf segments were inoculated with spores of leaf rust (80 spores per $\mathrm{cm}^{2}$; Fig. $6 \mathrm{~B}$ and $\mathrm{C}$ ). A significant reduction of rust colonies was observed on leaf segments of afp line 35/6 (36\% compared with the wild type) and chitinase II lines 6/8 (30\%), 25/7 (52\%), and 9/9 (37\%). The very low afp-expressing line 33/3 (not shown) exhibited no significantly improved resistance just as plants only expressing the bar or the barley rip I gene. At very high inoculum densities of rust spores $(\geq 300$ spores per $\mathrm{cm}^{2}$ ), a differentiation with respect to the formation of fungal colonies between nontransgenic controls and afp- or chitinase II-expressing lines, was no longer detectable (not shown). None of the four barley rip I-expressing wheat lines exhibited a detectable reduction of disease symptoms.

The results in Figure 6 were obtained in inoculation experiments with the powdery mildew isolate $1998 \mathrm{~W}$ and leaf rust isolate $77 \mathrm{WxR}$. The afp-expressing lines $33 / 3$ and $35 / 6$, the chitinase II-expressing lines $6 / 8$ and $9 / 9$, and the rip Iexpressing lines 28/6 and 32/1 were used as random samples in two repetitions with one further leaf rust (167WxR176) and two powdery mildew isolates $(1 \mathrm{R}, 5 \mathrm{R})$ at inoculum densities of approximately 80 and 100 spores per $\mathrm{cm}^{2}$, respectively. No significant differences to the results of the aforementioned isolates (1998W and $77 \mathrm{WxR}$ ) were obtained. Thus, the improved resistance of chitinase II- and afp-expressing plants and the lack of resistance of rip I-expressing plants do not seem to be isolate-specific phenomenons.

\section{Ribosome inactivating activity.}

All known RIPs show inhibition of mammalian ribosomes (Hartley et al. 1996). Ribosome-inactivating activity of leaf

Table 2. Transgene-expressing lines per generation

\begin{tabular}{lccc}
\hline Examined transgenic lines & $\mathbf{T}_{\mathbf{0}}$ & $\mathbf{T}_{\mathbf{1}}$ & $\mathbf{T}_{\mathbf{2}}$ \\
\hline 4 afp & 3 & 3 & 3 \\
3 chitinase & 3 & 3 & 3 \\
5 rip & 5 & 4 & 4 \\
$\sum 12$ & 11 & 10 & 10 \\
\hline
\end{tabular}

extracts from barley rip I-expressing wheat lines was verified and confirmed with a cell-free rabbit reticulocyte lysate transcription-translation system. Clear inhibition of translation was found when extracts from plants of strong rip Iexpressing lines such as 32/1 were used (Fig. 7).

At the same protein concentration $(2.5 \mu \mathrm{g}$ per $\mathrm{ml})$, protein extracts of nontransgenic controls (wt) only slightly disturbed the synthesis of active luciferase in comparison to the buffer control.

\section{DISCUSSION}

Transgenic plants were produced at a transformation rate (approximately $0.9 \%$ ) that was comparable with rates cited by others for wheat (Becker et al. 1994; Vasil et al. 1993). Stable integration and inheritance of the chitinase II and the rip I gene from barley and the fungal afp gene was confirmed in all

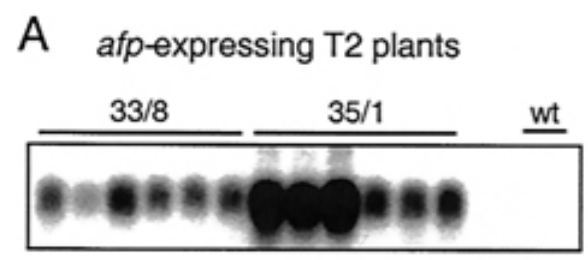

\section{B chitinase Il-expressing T2 plants}

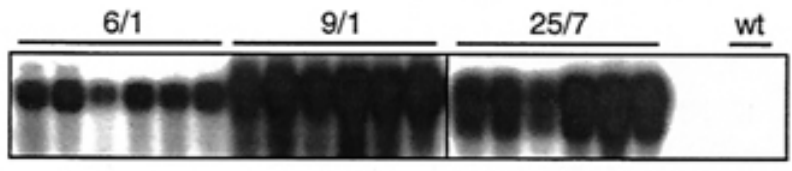

\section{C rip l-expressing T2 plants}

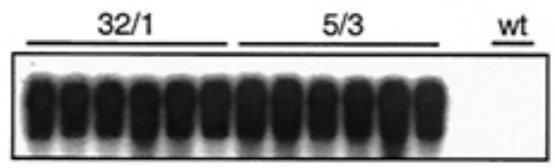

Fig. 4. Northern blot analyses of $T_{2}$ progeny. Total RNA of six individuals from different A, afp-, B, barley chitinase II-, or C, rip I-expressing wheat lines and wild-type control plants (wt) was hybridized to radioactively labeled, corresponding complete cDNAs.

\section{Progeny of chitinase II line 6/1}

$\mathrm{T} 1$

T2

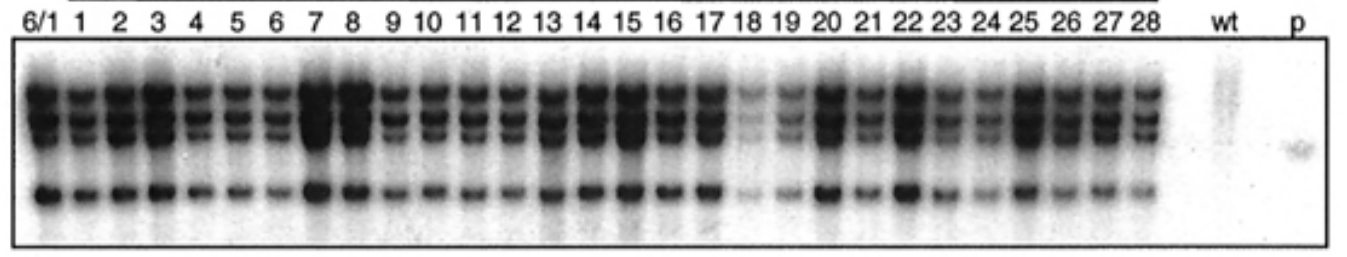

Fig. 3. Southern blot analysis of chitinase II $T_{1}$ plant $6 / 1$ and its $T_{2}$ progeny. Genomic DNA extracted from one $T_{1}$ and $28 T_{2}$ plants from chitinase II line $6 / 1$ and a wild-type control (wt) was hybridized to the radioactively labeled Ubiquitin 1 promoter PstI fragment. Identical pattern of hybridization signals can be observed in all individuals after restriction with EcoRI, cutting at one site in the pubi.chi construct, as indicated in lane p (linearized plasmid). 
examined generations $\left(\mathrm{T}_{0}\right.$ to $\left.\mathrm{T}_{3}\right)$. Stable expression of all three genes was proven by Northern blot analysis in three generations for 10 out of 12 examined lines. A correlation between expression levels and the number of integrated transgene copies was not obvious. This may be the result of positional effects or homology-dependent transgene inactivation caused by multiple copy integrations (Flavell 1994; Kumpatla et al. 1998).

Besides its moderate constitutive activity, heat stressinduced expression of the Ubiquitin 1 promoter from maize has been reported in different monocots such as maize (Christensen et al. 1992), rice (Takimoto et al. 1994), and, recently, for wheat (Clausen et al. 2000). The strong and fast induction (approximately tenfold within $1 \mathrm{~h}$ ) in rust-inoculated leaf tissue qualifies the Ubiquitin 1 promoter for the regulation of transgenes encoding antifungal proteins in wheat to inhibit leaf diseases such as rust or powdery mildew.

Thus, the heterologous expression of the fungal afp and the barley seed-specific chitinase II gene in wheat resulted in an enhanced resistance against mildew and rust, representatives of the Ascomycotina and Basidiomycotina subdivisions of higher fungi. Transgenic wheat lines exhibiting an improved resistance against mildew also showed an improved resistance against rust and vice versa. A general specificity of afp- or chitinase II-expressing lines with respect to their efficiency against one of these two pathogens has not been observed. A reduced number of spore-containing colonies (30 to 50\%, at an inoculum density of approximately 100 mildew or 80 rust spores per $\mathrm{cm}^{2}$ ) on the leaves of transgenic wheat lines could prevent or slow down an epidemic spread of these worldwide, economically important pathogens (Obst and Paul 1993; Wiese 1991).

The quantitative resistance of leaves from afp and chitinase II plants suggests that both antifungal proteins do not prevent the establishment of the plant-pathogen interaction but influence the expansion of both obligate biotrophic fungi. Until now, complete resistance against fungal pathogens has not been achieved by the expression of single genes encoding antifungal proteins. In reports on various transgenic plant species, expression of chitinase genes of different origin resulted in a quantitatively enhanced resistance, e.g., in tobacco (Broglie et al. 1991; Jach et al. 1995; Terakawa et al. 1997), rape seed (Broglie et al. 1991; Grison et al. 1996), rice (Lin et al. 1995), roses (Marchant et al. 1998), or wheat (Bliffeld et al. 1999). Small antifungal proteins such as $R s$-AFP2 from radish (Terras et al. 1995) and a thionin from Arabidopsis (Epple et al. 1997), which show structural similarities to the Ag-AFP (Campos-Olivas et al. 1995) that was used, also mediated a quantitative effect in transgenic tobacco against $\mathrm{Al}$ ternaria longipes and Arabidopsis against Fusarium oxysporum, respectively.

Although mediating an improved resistance against the soilborne fungus Rhizoctonia solani in transgenic tobacco (Jach et al. 1995; Logemann et al. 1992), the barley rip I gene was ineffective in our wheat plants to powdery mildew and leaf rust infections, independent of the transcript level in the four transgenic lines. The successful application in transgenic tobacco (Jach et al. 1995; Logemann et al. 1992) might be caused by a sensitivity of $R$. solani against barley RIP I or the assistance of endogenous tobacco factors that have no pendant in wheat. Recent reports in which a cofactor dependence for full activity of barley seed RIP I was observed support the latter supposition (Brigotti et al. 1998; Carnicelli et al. 1997). The resistance of the barley rip I gene-expressing tobacco against biotrophic fungi has not been reported. Thus, our findings in transgenic wheat might reflect the only weak inhibitory effect on fungi observed in former in vitro assays (Leah et al. 1991). The translation inhibition in a mammalian reticulocyte lysate by extracts of rip I-expressing wheat plants indicates that an active gene product is synthesized and that plant ribosomes are insensitive to RIP I, confirming the findings of others (Hartley et al. 1996; Leah et al. 1991; Taylor et al. 1994). Our data do not support the assumption of Bieri and coworkers (2000) that barley RIP I possibly is toxic for plant ribosomes and inhibits plant regeneration when expressed cytosolically in transgenic wheat.

The dependence of the resistance of $a f p$ and chitinase II plants on the inoculum dose resembles the situation in nontransgenic plants, where rapid and effective activation of defense mechanisms is essential for the successful inhibition of pathogen attack (Elstner et al. 1996; Yang et al. 1997). The dose-dependent resistance of afp and chitinase II wheat plants might be sufficient in the field, provided that the disease is at the beginning of its development and has not reached epidemic extent.

The applied detached leaf assay, which has long been used in obligate biotroph studies and to monitor pathogen populations (Limpert et al. 1988), is sensitive enough to detect differences in the resistance of individual lines. Clearly, what awaits confirmation is the reliability of the observed improved resistance of afp-and chitinase II-expressing wheat plants in the field where, in general, environmental factors strongly influence the resistance of cultivars.

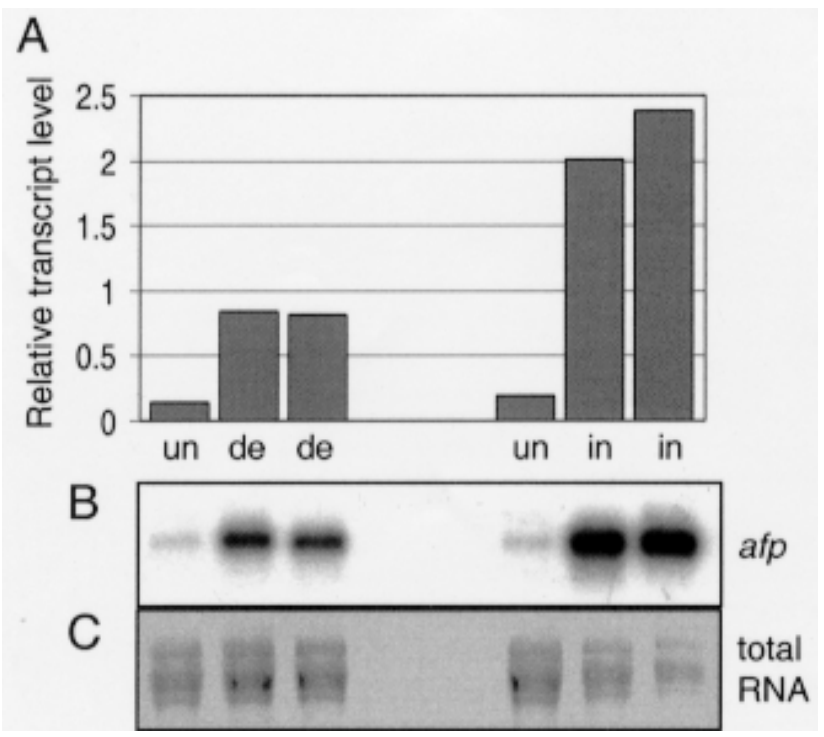

Fig. 5. Inducible Ubiquitin 1 promoter activity. afp transcript levels were quantified approximately $\mathbf{A}$, after isolation of total RNA from leaves of unstressed plants (un), detached leaf segments (de) incubated for $1 \mathrm{~h}$ at $20^{\circ} \mathrm{C}$, and plant leaves that were inoculated with rust spores $1 \mathrm{~h}$ before RNA isolation (in). Quantification was carried out in two independent experiments. Total RNA isolated from wheat line $35 / 6$ after C, gel electrophoresis was blotted and hybridized to $\mathbf{B}$, radioactively labeled afp cDNA. 
A

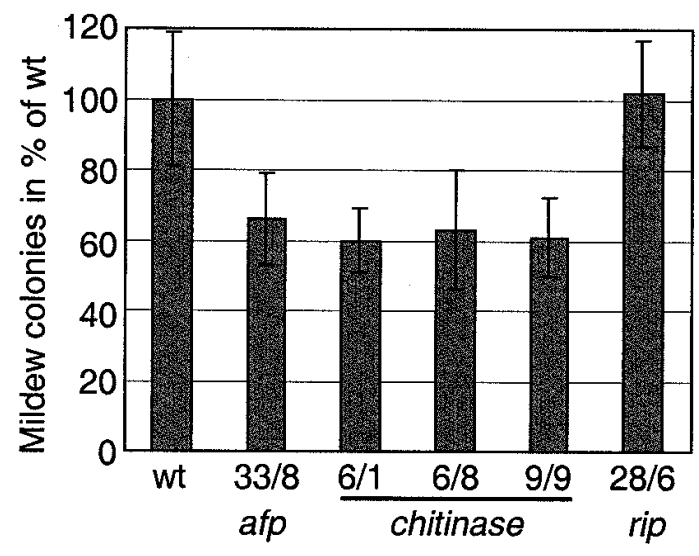

B

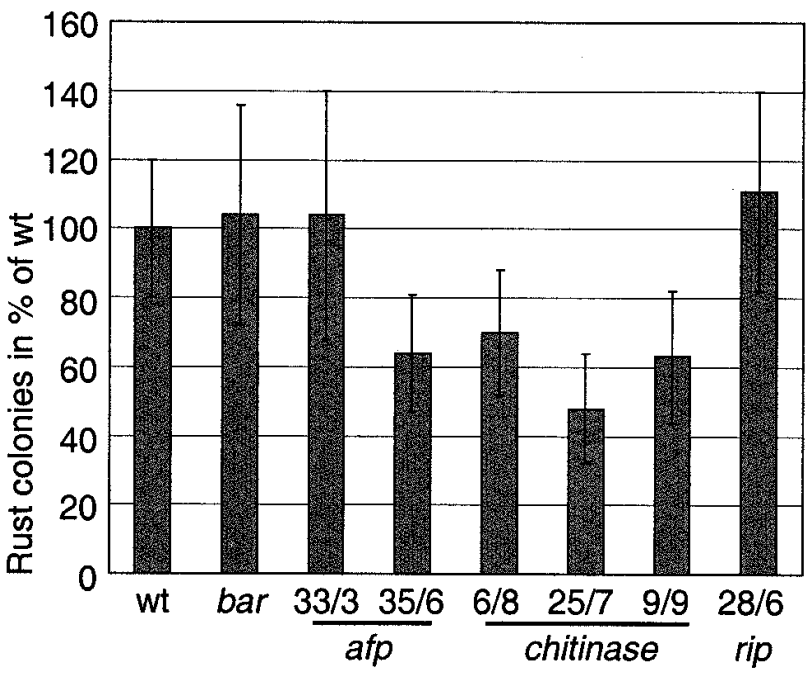

C
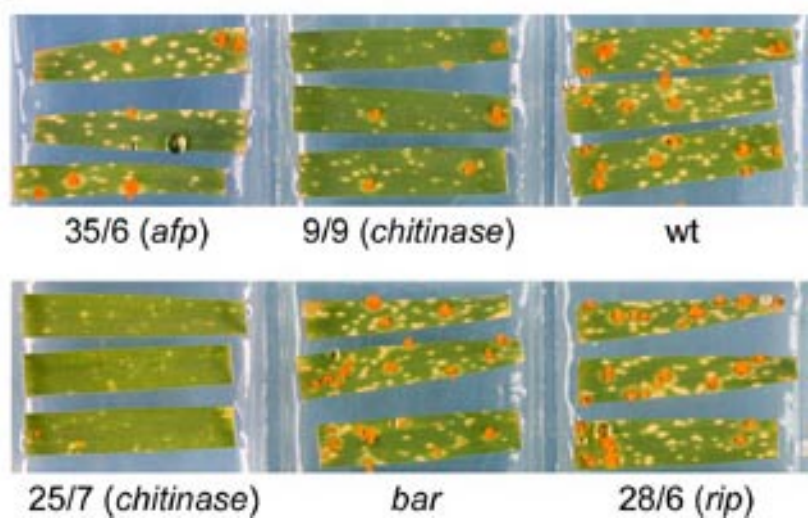

Fig. 6. Infection of detached leaves with $\mathbf{A}$, mildew or $\mathbf{B}$ and $\mathbf{C}$, rust spores. The average number of fungal colonies on transgenic leaves was scored and compared to the number on nontransgenic (wt) leaves (in percentages). Plants per wheat line (8-15) were tested in three repetitions with mildew (isolate 1998W) or five repetitions with rust (isolate 77WxR) using an inoculum density of approximately 100 or 80 spores $/ \mathrm{cm}^{2}$, respectively. Wheat lines 33/3, 33/8, and 35/6 are expressing the afp gene; 6/1, 6/8, $25 / 7$, and $9 / 9$ are expressing barley chitinase II; $28 / 6$ is expressing barley rip I; and bar is expressing the bar gene. Standard deviations of mean values are indicated as $\mathbf{A}$ and $\mathbf{B}$, error bars. Rust-inoculated leaf segments from afp line 35/6, chitinase II lines 9/9 and 25/7, rip I line 28/6, and bar line and control (wt) $\mathbf{C}, 12$ days after inoculation.
Nearly all of the approaches applied in wheat for the improvement of fungal resistance were first realized in dicot plant systems, principally tobacco, which is more amenable to genetic transformation than is wheat. Results obtained with transgenic dicots cannot always be extrapolated to cereals, however, because of the different endogenous backgrounds and spectra of pathogens, as indicated by the barley rip I gene.

The synergistic effects of defense-related proteins such as chitinase, $\beta$-1,3-glucanase, and RIP were demonstrated in vitro (Leah et al. 1991; Mauch et al. 1988) and confirmed in transgenic tobacco and tomato (Jach et al. 1995; Jongedijk et al. 1995; Zhu et al. 1994). Additive or similar synergistic effects also might be achieved in wheat by combining the different antifungal proteins via crosses between wellcharacterized lines, each expressing a single antifungal transgene. Homozygous progeny plants with combined antifungal genes showing quantitative fungal resistance could then be used for further crosses with elite wheat cultivars and would allow simple marker-assisted breeding in contrast to the often difficult-to-detect, natural quantitative resistance traits.

\section{MATERIALS AND METHODS}

Plant material and wheat transformation.

Cultivation of Florida and Combi in the greenhouse, preparation of immature embryos for particle bombardment, and selection conditions were performed as described (Becker et al. 1994). A modified MS medium (Murashige and Skoog 1962) composed of major and minor elements and $30 \mathrm{~g}$ of sucrose without vitamins per liter (D. Becker, unpublished) was used as basal medium for in vitro culture.

\section{Expression vectors.}

Plasmids p35SAcS, pubi2afp, pubi2rip, and pGJ38 were provided by P. Eckes (Aventis CropScience). The HindII site of plasmid pubi.cas (D. Becker, unpublished) between the Ubiquitin 1 promoter from maize and Tnos served as a recipient for the complete, filled-in EcoRI restriction fragment of the barley chitinase II cDNA (1021 bp) from construct pGJ38.

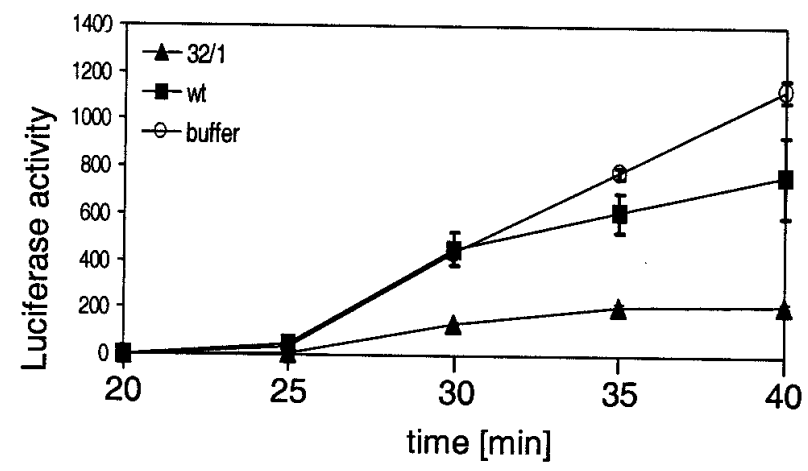

Fig. 7. Inhibition of a rabbit reticulocyte lysate coupled transcriptiontranslation system by total protein extracts. At 24 min after the lysate started to synthesize luciferase from plasmid DNA, leaf protein extracts were added. The time course of luciferase activity (arbitrary units) was scored reflecting the effect of protein extract from the wild-type control (wt), rip I-expressing line (32/1), or extraction buffer (buffer). Curves represent the mean values of three repetitions with $2.5 \mu \mathrm{g}$ of total protein per ml reaction volume with standard deviations as error bars. 


\section{Southern blot analysis.}

Total genomic DNA was isolated from leaf tissue with a rapid extraction protocol (Dellaporta et al. 1983). Uncut and restriction enzyme-digested genomic DNA ( $20 \mu \mathrm{g}$ per lane) or $20 \mathrm{pg}$ of restricted plasmid DNA (positive control) were separated in a $0.8 \%$ agarose gel, blotted onto a Hybond NX nylon membrane (Amersham, Braunschweig, Germany), and hybridized to ${ }^{32} \mathrm{P}$-labeled probes synthesized from DNA restriction fragments (1.5-kb Ubiquitin1 promoter Pst fragment or 0.56$\mathrm{kb}$ Bam HI bar fragment) with the Rediprime DNA labeling system (Amersham). Nonincorporated nucleotides were removed with Microspin columns HR S300 (Pharmacia, Erlangen, Germany), and hybridization was carried out as described (Sauter 1997). Blots were washed successively at $68^{\circ} \mathrm{C}$ for 10 min in $1 \times \mathrm{SSC}(1 \times \mathrm{SSC}$ is $0.15 \mathrm{M} \mathrm{NaCl}$ plus $0.015 \mathrm{M}$ sodium citrate); $1 \times \mathrm{SSC}, 0.1 \%$ sodium dodecyl sulfate (SDS) $(\mathrm{wt} / \mathrm{vol}) ; 0.5 \times \mathrm{SSC}, 0.1 \% \mathrm{SDS}$; and $0.2 \times \mathrm{SSC}, 0.1 \% \mathrm{SDS}$.

\section{RNA blot analysis.}

Total RNA was extracted from leaf tissue with TrizolReagent ultrapure (GIBCO-BRL, Karlsruhe, Germany). Total RNA $(12 \mu \mathrm{g})$ was separated, blotted, and hybridized under conditions as described (Sauter 1997). ${ }^{32} \mathrm{P}$-labeled probes were prepared, as described above for Southern blot analysis, with restriction fragments containing the complete cDNAs of $a f p$, barley chitinase II, or barley rip I. The blots were washed at $70^{\circ} \mathrm{C}$, as they were for the Southern blots, but with $1 \%$ SDS instead of $0.1 \%$ SDS. To prevent an induction of endogenous wheat chitinase genes, plants were cultivated aseptically. Moreover, Northern blots were washed twice with $0.1 \%$ SDS at $100^{\circ} \mathrm{C}$ for $30 \mathrm{~min}$ and hybridized additionally with a radioactively labeled barley $\beta$-1,3-glucanase (Leah et al. 1991) probe from plasmid pGJ38 (data not shown). This hybridization functioned as an internal control because chitinase and $\beta$ 1,3-glucanase are simultaneously induced in wheat (Caruso et al. 1999; Münch-Garthoff et al. 1997). Only Southern-positive chitinase II plants that showed no signal in Northern blot analysis after hybridization with the $\beta-1,3$-glucanase probe were designated as plants expressing barley chitinase II.

\section{Inoculation experiments.}

For inoculation with conidia of different isolates of $E$. graminis f. sp. tritici, field isolate 1998W (Epilogic, Weihenstephan, Germany) and single-spore isolates $1 \mathrm{R}$ and $5 \mathrm{R}$ were maintained on the highly susceptible cultivars Kanzler and Florida. Inoculation experiments were carried out as described (Limpert et al. 1988). Briefly, for mildew inoculation, three to four leaf segments, $3 \mathrm{~cm}$ in length, were cut from the middle section of primary leaves of up to $15 \mathrm{~T}_{2}$ seedlings per wheat line and placed on $0.5 \%$ (wt/vol) agar containing $30 \mathrm{mg}$ of benzimidazole per liter. For each inoculation experiment, samples of all examined lines were inoculated together in a settling tower with freshly harvested conidia to guarantee the same inoculation densities. The inoculation density was determined for each experiment by microscopical counting of spores on the agar. Leaf segments were incubated in a climate chamber at $16^{\circ} \mathrm{C}$ under continuous light $\left(70 \pm 5 \mu \mathrm{E}\right.$ per $\mathrm{m}^{2}$ per $\left.\mathrm{s}\right)$. The number and size of formed colonies was evaluated 9 and 13 days postinoculation. Different inoculation densities of approximately 100, 300 , and 600 spores per $\mathrm{cm}^{2}$ were used.
Inoculations with leaf rust spores (single spore isolates. $77 \mathrm{WxR}$ and $167 \mathrm{WxR} 176$ ) were carried out in a similar manner to mildew inoculations with the following modifications. Leaf segments were placed on agar containing $40 \mathrm{mg}$ of benzimidazole per liter, and came from secondary and tertiary leaves of seedlings. Inoculation densities of about 80, 300, and 600 spores per $\mathrm{cm}^{2}$ were applied. Directly after inoculation, samples were incubated in the dark for $24 \mathrm{~h}$ at $20^{\circ} \mathrm{C}$ and $100 \%$ relative humidity, followed by incubation under light conditions (16 h per day; $150 \pm 20 \mu \mathrm{E}$ per $\mathrm{m}^{2}$ per s), until 12 days after inoculation when final evaluation (number of formed colonies) took place. For the quantification of the inducible Ubiquitin1 promoter activity (Fig. 5), approximately 600 spores per $\mathrm{cm}^{2}$ were applied. Statistical analysis was performed by means of the Scheffe test and the Student $t$ test, with a significance level of $5 \%$.

\section{Ribosome-inactivating activity of protein extracts.}

Total leaf protein was extracted with a Borax buffer (200 $\mathrm{mM}$ boric acid; $2 \mathrm{mM}$ Borax; $250 \mathrm{mM} \mathrm{KCl} ; 20 \mathrm{mM}$ Tris- $\mathrm{HCl}$, $\mathrm{pH}$ 6.8; glycerol 50\% [vol/vol]; and protease inhibitor cocktail [complete Mini; Roche, Mannheim, Germany]). A cell-free rabbit reticulocyte lysate (TNT T7 Quick Coupled Transcription-Translation System; Promega, Madison, WI, U.S.A.) was used to measure ribosome-inactivating activity of leaf extracts from rip I-expressing and wild-type wheat plants. The lysate synthesized luciferase for $24 \mathrm{~min}$ from plasmid DNA as a template before extraction buffer (Fig. 7) or total leaf protein extracts from rip I-expressing (32/1) or control plants (wt) were added. The time course of luciferase activity was measured at intervals of $5 \mathrm{~min}$ at $30^{\circ} \mathrm{C}$ in reaction volumes of $25 \mu \mathrm{l}$ containing $0.5 \mu \mathrm{g}$ of plasmid DNA and total leaf protein with concentrations of 2.5 (Fig. 7), 5, or $25 \mu \mathrm{g}$ (not shown) per milliliter reaction mix.

\section{ACKNOWLEDGMENTS}

We are grateful to K. Flath and U. Walther (Bundesanstalt für Züchtungsforschung, Kleinmachnow and Biologische Bundesanstalt Aschersleben, Germany) for the fungal isolates and assistance with the resistance assays. We also thank M. Jäger-Gussen and C. Knaak (Aventis CropScience $\mathrm{GmbH}$ ) for their assistance with the evaluation and statistical analysis of the mildew assays and A. Milligan for critical reading of the manuscript. This work was supported by Aventis CropScience $\mathrm{GmbH}$.

\section{LITERATURE CITED}

Becker, D., Brettschneider, R., and Lörz, H. 1994. Fertile transgenic wheat from microprojectile bombardment of scutellar tissue. Plant J. 5:299-307.

Bieri, S., Potrykus, I., and Fütterer, J. 2000. Expression of active barley seed ribosome-inactivating protein in transgenic wheat. Theor. Appl. Genet. 100:755-763.

Bliffeld, M., Mundy, J., Potrykus, I., and Fütterer, J. 1999. Genetic engineering of wheat for increased resistance to powdery mildew disease. Theor. Appl. Genet. 99:755-760.

Brigotti, M., Keith, G., Pallanca, A., Carnicelli, D., Alvergna, P., Dirheimer, G., Montanaro, L., and Sperti, S. 1998. Identification of the tRNAs which up-regulate agrostin, barley RIP and PAP-S, three ribosome-inactivating proteins of plant origin. FEBS Lett. 431:259262.

Broglie, K., Chet, I., Holliday, M., Cressman, R., Biddle, P., Knowlton, S., Mauvais, C. J., and Broglie, R. 1991. Transgenic plants with enhanced resistance to the fungal pathogen Rhizoctonia solani. Science 
254:1194-1197.

Campos-Olivas, R., Bruix, M., Santoro, J., Lacadena, J., Martinez del Pozo, A., Gavilanes, J. G., and Rico, M. 1995. NMR solution structure of the antifungal protein from Aspergillus giganteus: Evidence for cysteine pairing isomerism. Biochemistry 34:3009-3021.

Carnicelli, D., Brigotti, M., Alvergna, P., Pallanca, A., Sperti, S., and Montanaro, L. 1997. Cofactor requirement of ribosome-inactivating proteins from plants. J. Exp. Bot. 48:1519-1523.

Caruso, C., Chilosi, G., Caporale, C., Leonardi, L., Bertini, L., Magro, P., and Buonocore, V. 1999. Induction of pathogenesis-related proteins in germinating wheat seeds infected with Fusarium culmorum. Plant Sci. 140:7-97.

Christensen, A. H., Sharrock, R. A., and Quail P. H. 1992. Maize polyubiquitin genes: Structure, thermal perturbation of expression and transcript splicing, and promoter activity following transfer to protoplasts by electroporation. Plant Mol. Biol. 18:675-689.

Clausen, M., Kräuter, R., Schachermayr, G., Potrykus, I., and Sautter, C. 2000. Antifungal activity of a virally encoded gene in transgenic wheat. Nat. Biotechnol. 18:446-449.

Dellaporta, S. L., Wood, J., and Hicks, J. B. 1983. A plant DNA minipreparation: Version II. Plant Mol. Bio. Rep. 4:19-21.

Elstner, E. F., Osswald, W., and Schneider, I., eds. 1996. Phytopathologie: Allgemeine und Biochemische Grundlagen. Spektrum Akademischer Verlag, Heidelberg, Germany.

Epple, P., Apel, K., and Bohlmann, H. 1997. Overexpression of an endogenous Thionin enhances resistance of Arabidopsis against Fusarium oxysporum. Plant Cell 9:509-520.

Flavell, R. B. 1994. Inactivation of gene expression in plants as a consequence of specific sequence duplication. Proc. Natl. Acad. Sci. USA 91:3490-3496.

Grison, R., Grezes-Besset, B., Schneider, M., Lucante, N., Olsen, L., Leguay, J.-J., and Toppan, A. 1996. Field tolerance to fungal pathogens of Brassica napus constitutively expressing a chimeric chitinase gene. Nat. Biotechnol. 14:643-646.

Hancock, E. W., and Lehrer, R. 1998. Cationic peptides: A new source of antibiotics. Tibtech 16:82-88.

Hartley, M. R., Chaddock, J. A., and Bonness, M. S. 1996. The structure and function of ribosome-inactivating proteins. Trends Plant Sci. 1:254-260.

Jach, G., Görnhardt, B., Mundy, J., Logemann, J., Pinsdorf, E., Leah, R., Schell, J., and Maas, C. 1995. Enhanced quantitative resistance against fungal disease by combinatorial expression of different barley antifungal proteins in transgenic tobacco. Plant J. 8:97-109.

Jongedijk, E., Tigelaar, H., Van Roekel, J. S. C., Bres-Vloemans, S. A., Dekker, I., Van den Elzen, P. J. M., Cornelissen, B. J. C., and Melchers, L. S. 1995. Synergistic activity of chitinases and beta-1,3glucanases enhances fungal resistance in transgenic tomato plants. Euphytica 85:173-180.

Kitajima, S., and Sato, F. 1999. Plant pathogenesis-related proteins: Molecular mechanisms of gene expression and protein function. J. Biochem. 125:1-8.

Kumpatla, S. P., Chandrasekharan, M. B., Iyer, L. M., Li, G., and Hall, T. C. 1998. Genome intruder scanning and modulation systems and transgene silencing. Trends Plant Sci. 3:97-104.

Lacadena, J., Martinez del Pozo, A., Gasset, M., Patino, B., CamposOlivas, R., Vazquez, C., Martinez-Ruiz, A., Mancheno, J. M., Onaderra, M., and Gavilanes, J. G. 1995. Characterization of the antifungal protein secreted by the mould Aspergillus giganteus. Arch. Biochem. Biophys. 324:273-281.

Leah, R., Tommerup, H., Svendsen, I., and Mundy, J. 1991. Biochemical and molecular characterization of three barley seed proteins with antifungal properties. J. Biol. Chem. 266:1464-1473.

Limpert, E., Andrivon, D., and Felsenstein, F. G. 1988. Influence of different benzimidazole concentrations in agar medium on senescence of wheat leaf segments and on growth and sporulation of the wheat powdery mildew pathogen. J. Plant Dis. Prot. 95:301-306.

Lin, W., Anuratha, C. S., Datta, K., Potrykus, I., Muthukrishnan, S., and Datta, S. K. 1995. Genetic engineering of rice for resistance to sheath blight. Bio/Technology 3:686-691.

Logemann, J. D., Jach, G., Tommerup, H., Mundy, J. D., and Schell, J. P. 1992. Expression of a barley ribosome-inactivating protein leads to increased fungal protection in transgenic tobacco plants. Bio/Technology 10:305-308.

Marchant, R., Davey, M. R., Lucas, J. A., Lamb, C. J., Dixon, R. A., and Power, J. B. 1998. Expression of a chitinase transgene in rose (Rosa hybrida L.) reduces development of blackspot disease (Diplocarpon rosae Wolf). Mol. Breed. 4:187-194.

Mauch, F., Mauch-Mani, B., and Boller, T. 1988. Antifungal hydrolases in pea tissue II. Inhibition of fungal growth by combinations of chitinase and beta-1,3-glucanase. Plant Physiol. 88:936-942.

Murashige, T., and Skoog, F. 1962. A revised medium for rapid growth and bioassays with tobacco tissue cultures. Plant Physiol. 15:473-497.

Münch-Garthoff, S., Neuhaus, J.-M., Boller, T., Kemmerling, B., and Kogel, K.-H. 1997. Expression of beta-1,3-glucanase and chitinase in healthy, stem-rust-affected and elicitor-treated near-isogenic wheat lines showing $\mathrm{Sr} 5$ - or $\mathrm{Sr} 24$-specified race-specific rust resistance. Planta 201:235-244.

Obst, A., and Paul, V. H. 1993. Krankheiten und Schädlinge des Getreides. 1st ed. Th. Mann Verlag, Gelsenkirchen-Buer, Germany.

Oerke, E. C., Dehne, H. W., Schönbeck, F., and Weber, A. 1994. Crop Production and Crop Protection. Elsevier Science, Amsterdam.

Sauter, M. 1997. Differential expression of a CAK (cdc2-activating kinase)-like protein kinase, cyclins and cdc2 genes from rice during the cell cycle and in response to gibberellin. Plant J. 11:181-190.

Stintzi, A., Heitz, T., Prasad, V., Wiedemann-Merdingoglu, S., Kauffmann, S., Geoffroy, P., Legrand, M., and Fritig, B. 1993. Plant "pathogenesis-related" proteins and their role in defense against pathogens. Biochimie 75:687-706.

Takimoto, I., Christensen, A. H., Quail, P. H., Uchimiya, H., and Toki, S. 1994. Non-systemic expression of a stress-responsive maize polyubiquitin gene (Ubi-1) in transgenic rice plants. Plant Mol. Biol. 26:1007-1012.

Taylor, S., Massiah, A., Lomonossoff, G., Roberts, L. M., Lord, J. M., and Hartley, M. 1994. Correlation between the activities of five ribosome-inactivating proteins in depurination of tobacco ribosomes and inhibition of tobacco mosaic virus infection. Plant J. 5:827-835.

Terakawa, T., Takaya, N., Horiuchi, H., Koike, M., and Takagi, M. 1997. A fungal chitinase gene from Rhizopus oligosporus confers antifungal activity to transgenic tobacco. Plant Cell Rep. 16:439-443.

Terras, F. R. G., Eggermont, K., Kovaleva, V., Raikhel, N. V., Osborn, R. W., Kester, A., Rees, S. B., Torrekens, S., Van Leuven, F. Vanderleyden, J., Cammue, B. P. A., and Broekaert, W. F. 1995. Small cysteine-rich antifungal proteins from radish (Raphanus sativus L.): Their role in host defense. Plant Cell 7:573-588.

Vasil, V., Srivastava, V., Castillo, A. M., Fromm, M. E., and Vasil, I. K. 1993. Rapid production of transgenic wheat plants by direct bombardment of cultured immature embryos. Bio/Technology 11:1553-1558.

Wiese, M. V. 1991. Compendium of Wheat Diseases. American Phytopathological Society, St. Paul, MN, U.S.A.

Wnendt, S., Ulbrich, N., and Stahl, U. 1994. Molecular cloning, sequence analysis and expression of the gene encoding an antifungalprotein from Aspergillus giganteus. Curr. Genet. 25:519-523.

Yang, Y., Shah, J., and Klessig, D. F. 1997. Signal perception and transduction in plant defense responses. Gene Dev. 11:1621-1639.

Zhu, Q., Maher, E. A., Masoud, S., Dixon, R. A., and Lamb, C. J. 1994. Enhanced protection against fungal attack by constitutive coexpression of chitinase and glucanase genes in transgenic tobacco. Bio/Technology 12:807-812. 